\title{
A historicidade do cinema ${ }^{1}$ Historicity of cinema
}

\section{Jacques Rancière ${ }^{2}$}

TTexto original: RANCIÈRE, Jacques. "L'historicité du cinema". In: DE BAECQUE, Antoine; DELAGE, Christian (Orgs.). De l'histoire au cinema. Paris: Compléxe, 1998. p. 45-60. Tradução: André Fabiano Voigt (professor associado do Programa de Pós-Graduação em História Social da Universidade Federal de Uberlândia) e Maurício José de Sousa Júnior (doutorando em História Social pela Universidade Federal de Uberlândia).

ªacques Rancière (1940-) é filósofo e professor emérito da Universidade de Paris VIII. Atualmente tem dedicado seu trabalho à compreensão das relações entre estética e política. É autor de A partilha do sensível, O espectador emancipado e $\mathrm{O}$ destino das imagens. 
Resumo: este artigo de Jacques Rancière, publicado originalmente em 1998 no livro De l'histoire au cinéma, organizado por Antoine de Baecque e Christian Delage, trata da historicidade do cinema, na medida em que esta historicidade está intimamente relacionada ao "regime estético da arte", que é um regime de compreensão da arte, em sua distinção entre o sensível e o pensável. O cinema, analisado no interior do "regime estético", relaciona-se com sua historicidade na medida em que está entrelaçado em três acepções da palavra "história": o tipo de trama em que um filme consiste, a função de memorialização que ele cumpre e a maneira como atesta uma participação em um destino comum.

Palavras-chave: história; cinema; Jacques Rancière; regime estético.

Abstract: this article of Jacques Rancière, originally published in 1998 in the book De l'histoire au cinéma, organized by Antoine de Baecque and Christian Delage, covers the historicity of the cinema, since this historicity is closely related to the "aesthetic regime of art," which is a regime of comprehension of art, in its distinction between sensible and thinkable. Cinema, analyzed within the "aesthetic regime," relates to its historicity because it is intertwined in three senses of the word "history": type of plot in which a movie is made up, function of memorialization that it accomplishes, and the way it certifies a participation in a common destiny.

Keywords: history; cinema; Jacques Rancière; aesthetic regime. 
Existem duas maneiras clássicas de atar cinema e história, fazendo de um de seus termos o objeto do outro. Trata-se da história como objeto do cinema, considerado em sua capacidade de prestar contas dos eventos de um século, do estilo de uma época, de uma maneira de viver em um dado momento. Ou se tem, ao contrário, o cinema como objeto da história, a qual estuda o advento de um novo entretenimento, as formas de sua indústria ou de seu porvir artístico, do devir das formas que o caracterizam. Ora, penso que as questões mais interessantes se instalam somente quando nos separamos desta relação sujeito/objeto e tentamos tomar em conjunto os dois termos, ver como as noções de cinema e de história são interdependentes e compõem juntas uma história. Trata-se aqui de colocar à prova uma hipótese: o cinema tem uma relação intrínseca com uma certa ideia de história e com a historicidade das artes a que ele é atado. O tempo do cinema é o tempo de uma história e de uma historicidade determinadas. O cinema não é simplesmente uma arte que surgiu mais tarde que as outras porque dependeu de desenvolvimentos técnicos e científicos ocorridos no século XIX e que, uma vez constituído, teria uma história do mesmo tipo que as outras (um desenvolvimento de suas técnicas, de suas escolas e de seus estilos, em relação com o desenvolvimento das formas de comércio, da política e da cultura etc.). O cinema não vem “após” as outras artes apenas por razões objetivas. Ele pertence a um tempo específico, determinado por uma certa ideia de história enquanto categoria de um destino comum. Ligado a uma ideia de arte aliada a esta ideia de história e que estabelece, assim, uma conexão específica a um certo número de possibilidades pertencentes à técnica, à arte, ao pensamento e à política. Por exemplo, ele conecta uma ideia de agente histórico ao tipo de imagem do homem que produziu suas técnicas de gravação e de projeção. O cinema, nos diz Godard, em seu Histoire(s) du cinema (História(s) do cinema, 1988-1998), não é uma arte nem uma técnica, é um mistério. Mas o "mistério" é ele mesmo uma certa ideia do par arte/técnica. A ideia de uma arte que é algo além da própria arte: o traçado e a sacralização de um gesto do homem que desenha uma ideia da comunidade humana. É a ideia de uma técnica que não é somente técnica, mas um modo específico do sensível, o modo de uma matéria arrancada à solidez e à instrumentalidade das coisas, apropriada à morada da comunidade humana. Neste "mistério" se determinou uma certa historicidade do homem que o cinema não se limita em registrar, mas que ele desperta por seu dispositivo técnico e artístico.

O cinema, segundo esta hipótese, pertence a uma certa historicidade e sua história pertence à história desta historicidade (à história que esta historicidade determina e ao destino dela). Esta visão das coisas se opõe claramente a uma 
certa ideia de ciência histórica que quer separar a ciência da história - a "ciência dos homens no tempo" da qual falava Marc Bloch - da noção de história como modalidade do tempo da comunidade humana. Assim, o manifesto de uma escola ${ }^{3}$ separava o trabalho científico que consiste em fazer a história que convocava os homens e as massas a fazerem história. Esta separação me parece frágil. Certamente uma ciência não é um modo de consciência. Mas a ciência de "fazer história" não depende menos de uma certa ideia de história como algo que é feito por um sujeito, ou alguma coisa que ocorre a um sujeito - (seja ele $)^{4}$ o príncipe ou o povo, a humanidade ou o Mediterrâneo, independentemente das diversas as formas como as propriedades ou os acidentes desse sujeito são pensados. Assim, para que o cinema seja objeto da história, e para que o cineasta "represente" a história, é necessário que uma certa historicidade vincule um ao outro. E uma historicidade é, em si mesma, uma combinação de várias "histórias". Porque "história” se diz em vários sentidos, e a relação entre cinema e história é uma relação entre três histórias. Primeiro, há a história no sentido tradicional do termo, a história enquanto coleção dos fatos e dos personagens memoráveis. A história enquanto prática de memória que se ocupou antigamente da crônica dos príncipes, ou da ilustração dos fatos dignos de serem considerados, retidos, imitados, e que hoje se ocupa prontamente, ao contrário, em celebrar os pequenos fatos que dão a cor de um tempo e de um modo de vida qualquer. Há, em segundo lugar, a história no sentido moderno, como potência de destino comum. Essa ideia comporta, em si mesma, duas. Primeiro, a ideia de um tempo orientado para cumprir uma direção específica, um tempo portador de promessas para aqueles que respeitarão as condições de sua sucessão e as tarefas que elas impõem - e, no sentido inverso, portador de ameaças para aqueles que desconhecem suas condições, negligenciam as tarefas a elas relacionadas ou pretendem antecipar seu efeito ${ }^{5}$. É também a ideia de uma potência reversível. Essa é a história que os homens fazem, o futuro que constroem juntos quando não se voltam mais à providência divina ou à sabedoria dos príncipes para conduzir seu destino. E é também a história que lhes faz, que lhes imprime um estilo específico, revolve o sentido de seus atos e devora aqueles que acreditavam ser seus artesãos.

\footnotetext{
${ }^{3}$ Referência à École des Annales. (N.T.)

${ }^{4}$ A frase diz respeito a um estudo que Rancière realizou em Os nomes da história, quando tratou do mar Mediterrâneo como testemunho e sujeito da história no livro de Fernand Braudel. RANCIÈRE, Jacques. Os nomes da história. São Paulo: Educ; Pontes, 1994. (N.T.)
}

${ }^{5}$ Esta frase faz alusão à noção teleológica de tempo da história, sobretudo a ideia de tempo orientado para a libertação humana da opressão do capital e da divisão em classes, defendido por alguns autores marxistas. (N.T.) 
Há, portanto, essas duas "histórias", o registro do memorável e a potência de destino comum. E há ainda uma terceira história que pertence ao conceito de artes representativas: a história como agenciamento próprio dos elementos da ficção, que Aristóteles chamava de mythos, a intriga ou reunião de ações; o que a pintura chamava istoria e que é a história proposta pela disposição das figuras sobre o quadro, pela maneira como suas atitudes, suas mãos, seus olhos se voltam para o "tema" do quadro, comentando sua presença ou se dirigindo ao espectador. Nas artes clássicas da representação, a questão da história é aquela da relação entre a reunião de atos, os modos expressivos e a função de memorialização. Uma pintura histórica é julgada pela relação de conveniência que a disposição dos corpos sobre o quadro mantém com a natureza dos personagens memoráveis representados e o valor exemplar da cena. É a partir deste ponto de vista que Diderot recusa a Caracalla de Greuze: ele confundiu os gêneros e fez de Caracalla o que ele é moralmente, um velhaco, esquecendo-se do que ele é "historicamente", um imperador romano. Ele confundiu duas ordens de grandeza e dois tipos de exemplaridade.

A era do cinema é a era da história em sua acepção moderna. Isso quer dizer que a inscrição cinematográfica da história vai se tornar complexa. Essa inscrição deverá fazer coincidir não mais duas, mas três "histórias": o tipo de trama em que um filme consiste, a função de memorialização que ele cumpre e a maneira como atesta uma participação em um destino comum. Tomamos como exemplo um filme do tipo "documentário", ou seja, um filme em que, em princípio, a função memorialística está em primeiro lugar e deve determinar o conjunto das funções históricas. Este filme é Listen to Britain (1941), de Humphrey Jennings. Realizado durante a Segunda Guerra Mundial, destinado a mostrar no exterior, especialmente no Canadá, a resistência inglesa aos ataques alemães, o filme pode parecer estritamente determinado, em sua "história", por sua finalidade. Ora, não é nada disso. Porque existem várias maneiras de cumprir essa função memorialística, conforme a maneira como nela se ligam as outras duas "histórias", a potência afirmada do destino comum e os recursos próprios da ficção cinematográfica. A prova é dada por um outro filme que o mesmo Jennings realizou, para os Estados Unidos, e que se intitula London can take it (1940). Este último mostra longamente o esforço militar da nação inglesa e os sofrimentos a que a população se submete, através das imagens de bombardeios, da cidade destruída, da população resistindo heroicamente à insegurança e à penúria. Tal poderia parecer o esquema obrigatório desse gênero de documentário. Ora, Listen to Britain não o obedece de maneira alguma. Não se podem ver os bombardeios, há poucas imagens de guerra, e os soldados são quase sempre filmados em períodos de 
lazer. Nós os vemos "cantar o romance" em um trem com acompanhamento de guitarra e de acordeão, dançar em um baile público, se espremer para escutar um número de canções ou um concerto de Mozart. E todo o filme se apresenta como um encadeamento de imagens de uma vida pacífica. É assim que a câmera nos instala, sem razão aparente, atrás de dois homens sentados sobre um banco olhando o pôr do sol na praia, antes de realizar um movimento lateral para uma luneta de observação que explica furtivamente todo o propósito do aparente vagueio militar: são os guardas-costeiros que monitoram a sempre possível vinda do inimigo. A trama fílmica repousa assim em uma subdeterminação sistemática do significado das imagens. Os guardas-costeiros são filmados pelas costas e contra a luz, como massas negras frente à repetição infinita das ondas e à repetição diária do pôr do sol. Esse visà-vis ${ }^{7}$ nega em sua presença sensível indiferente, a-significante, a função de vigilância que lhe dá significado. Assim ele apaga o inimigo, o alvo, a finalidade do olhar dessas massas negras que a câmera assenta diante do pôr do sol, tal como Flaubert, em Bouvard et Pécuchet, mostrava-nos Bouvard, esquecendo-se de Pécuchet e do propósito geológico de sua expedição, para deixar seu olhar perdido na indiferença infinita do espetáculo marítimo.

Que faz então este filme “documentário", esta obra de memória, para testemunhar a maneira pela qual o povo britânico, diante da história, assume o destino comum? De modo algum é suficiente responder que ele propõe as imagens de tranquilidade para ilustrar a mensagem de calma imperturbável de um povo sólido e fleumático. Pois as imagens são de um tipo bem particular: não são simplesmente dos instantanés ${ }^{8}$ da vida. Elas são os momentos a-significantes que pertencem especificamente à “economia” dos filmes de ficção. Uma ficção cinematográfica é, de fato, um encadeamento específico de dois tipos de sequências: das sequências finalizadas segundo a lógica representativa aristotélica, ou seja, os conjuntos de

\footnotetext{
${ }^{6}$ Em francês, "chanter le romance" significa um tipo de canção que se tornou comum na França a partir do final do século XVIII e, principalmente, no início do século XIX, em que o chamado "romance” é um tipo de música tocada em salões (canções, cançonetas ou noturnos) para uma ou duas vozes, acompanhadas pela harpa, violão ou cravo e, quando mais se aproximava da Restauração (1814), pelo novo instrumento em voga, o pianoforte. A tradução literal em português obviamente não abarca o sentido original da língua francesa. SCHNAPPER, Laure. Histoire de la musique. Chanter la romance. Napoleonica. 2010, n. 7. p. 3-20. Disponível em: <https://www.cairn.info/revue-napoleonica-la-revue-2010-1-page-3.htm>. Acesso em 25 set. 2017. (N.T.)

${ }^{7}$ Vis-à-vis foi mantido do original para não fugirmos da intencionalidade que o autor infere à expressão. Cara a cara ou olho no olho, enquanto traduções diretas, poderiam dar a noção de enfrentamento, distanciando-se da ideia expressada. (N.T.)

${ }^{8} \mathrm{~A}$ expressão em francês remete à fotografia instantânea e, talvez, à capacidade do cinema e da fotografia em captar instantes do cotidiano, em comparação com as fotografias de instantes realizadas no final do século XX, relembrando um primeiro tempo da fotografia em que o tempo de exposição era mais longo. (N.T.)
} 
ações, e das sequências não finalizadas, das sequências líricas que suspendem a ação e se subtraem ao imperativo do sentido para dar a ver, simplesmente, "a vida" em seu “despropósito", em sua existência bruta, sem razão. Assim podem ser encarados os dois personagens sentados diante do pôr do sol, um rosto visto atrás da janela, uma brincadeira de roda no pátio da escola etc. Uma ficção comum se constrói pelo retorno da potência de atestação dramática aliada a uma montagem causal e ao ritmo de ações e da potência lírica que impõe, pelo suspense das razões e do ritmo, a sensação de existência.

O “documentário histórico” de Jennings adota uma lógica bem específica. É em seu âmago uma montagem desses momentos de suspensão da ficção. É pela montagem desses momentos a-significantes que ele significa a participação do povo inglês nas tarefas da história universal. Ele joga, portanto, segundo o espírito da poética romântica, sob a significância variável da imagem. Efetivamente, a poética romântica se opõe ao encadeamento aristotélico das ações "segundo a necessidade ou a verossimilhança", uma poética de signos, uma poética fundada sobre a potência de significação variável dos signos e das montagens de signos que formam o tecido de abertura: potência de expressão pela qual uma frase, um episódio, uma imagem se isolam para exprimir, por eles mesmos, a natureza e a tonalidade do conjunto; potência de correspondência pela qual os signos diversos entram em ressonância ou em dissonância; poder de metamorfose pelo qual uma combinação de signos se fixa em um objeto opaco ou se propaga de forma significante e viva.

O filme de Jennings joga com esta polivalência romântica das imagens. Mas ele pode fazê-lo em razão de uma afinidade particular da arte cinematográfica com a poética romântica. Esta afinidade mantém o fato de que a imagem cinematográfica é dupla em seu princípio. Ela é produzida, efetivamente, pela combinação de dois olhares: um olhar mecânico que grava e um olhar artístico que ordena a gravação. Essa é a combinação que se inscreve no encadeamento significante de imagens sub-significantes pelo qual Jennings mostra a ação histórica de ingleses quaisquer, tomados em suas atividades quaisquer. Esta participação de todos na grande história encontra sua expressão adequada na mediação artística exatamente adaptada a esta significância variável das imagens. Esta é, em si mesma, a forma de expressão que corresponde ao grande princípio da poética romântica: o igual valor de todo sujeito ao olhar da absoluta potência da arte. A trama histórica do documentário aplica o princípio romântico (não importa o que ou quem, são igualmente interessantes, igualmente apropriados à manifestação da arte) na demonstração de que todos participam da grande tarefa histórica. Porque o olho "mecânico", o olho imparcial da câmera, se oferece exemplarmente à revelação do interesse de toda coisa 
desinteressante, ele demonstra ser particularmente apto a figurar essa história nova que é o destino de todos, e de que todos fazem parte igualmente. É assim que uma certa ideia de agente histórico se vincula à potência estética do cinema.

Ainda é preciso entender o que essa "potência estética” significa. Para tanto, podemos retornar à fórmula já evocada por Godard: “nem uma arte, nem uma técnica; um mistério". Nessa fórmula, nós encontramos, facilmente, o eco das grandes declarações daqueles que, nos anos 1920, fundam a dignidade artística do cinema. O cinema - dizem eles todos - é mais que uma arte. Ele ultrapassa a tekhnè artística tanto em seu princípio como em seu resultado. Por um lado, ele não é só uma arte, "mas outra coisa, ainda melhor". Pois, nos diz Jean Epstein: "O que o distingue é que, através dos corpos, ele registra os pensamentos" (EPSTEIN, 1975). Essa potência de clarividência, que excede os poderes de toda tekhnè artística, o destina a superar a tradicional separação das produções da arte e das manifestações da vida. "O cinema é um encaminhamento para esta supressão da arte que excede a arte, sendo a vida", conforme diz Louis Delluc 9 .

Por que ao cinema é concedido o privilégio de ser mais que uma arte, de ser uma arte que se abre para além da arte? Porque o cinema aparece, em suas teorizações, como uma arte liberada de seu artifício. Ele é liberado, primeiro, das normas da representação, da obrigação de "fazer reconhecer", mas também de todas as regras que definem seu uso. O cinema é liberado, mais profundamente, dos modos de conexão interior e exterior, da causa e do efeito, em resumo, de todo o sistema psicológico da verossimilhança, ligado ao modo representativo da arte. É liberado, enfim, da vontade da arte, da vontade de fazer da arte. É essa tripla liberação que é atribuída ao dispositivo da duplicação - senão de destituição - do olho humano pelo olho mecânico. O olho mecânico é o olho verídico, o olho imparcial, sem pressupostos, o que substitui o que o olho vê pelo analogon da visibilidade que ele projeta tradicionalmente em uma superfície representativa. Ao mesmo tempo, ele substituiu as qualidades, características e expressões do sistema psicológico representativo pelas velocidades, os movimentos e as vibrações de energia, que é a identidade da matéria e do espírito. Ele é o "artista inteiramente honesto" do qual fala Epstein, o "sujeito sem consciência, ou seja, sem hesitações nem escrúpulos,

'Louis Delluc (1890-1924), teórico, cineasta, teatrólogo e roteirista, aparece em diversas citações do artigo de Rancière dialogando com os cineastas Jean Epstein, Dziga Vertov, Abel Gance, Élie Faure e Fritz Lang. Juntamente com Germaine Dulac e Ricciotto Canudo (este último o criador da expressão "sétima arte") contribuíram com o aprofundamento das discussões sobre o movimento chamado de impressionismo, muito presente nas primeiras décadas do cinema. Suas características acentuavam as diferenças nas imagens entre o claro e o escuro, o mistério e os afetos acentuados, antecipando o cinema noir e o expressionismo, defendendo a existência de uma nova linguagem marcada pela montagem. (N.T.) 
incorruptível, sem complacência nem erros possíveis", que não escreve o que vê pela simples razão de que ver e escrever são para ele a mesma coisa. Possui assim a capacidade de jogar para o alto o quase-visível que o sistema representativo construiu como tradução do pensamento e do sentimento. Esse olho exato vê a manifestação exata de um e do outro. Vê “o pensamento impresso em toques de ampères à tela”. E frente a ele está disposta uma humanidade exatamente clara, exatamente percebida em sua realidade física. Pois, nos diz ainda Epstein, "aquele olho vê, imagino, ondas para nós imperceptíveis, e o amor da tela contém o que amor algum havia contido até agora, sua justa dose de ultravioleta" 10 .

Em vez do dispositivo intencional de arte representativa, o cinema põe em ato o dispositivo de uma outra psyché e de uma outra physis, essa mesma que a ciência física moderna comprova. $\mathrm{O}$ olho da máquina transcreveu diretamente os movimentos do pensamento. A energia elétrica da matéria encontra a energia nervosa do espírito. Isso quer dizer que a arte cinematográfica é mais que uma arte, ela é um modo específico do sensível. É o modo como Godard a chamou pelo nome mallarmeano de mistério, corroborando assim a natureza "sobrenatural" ou "mística" que o cientista Jean Epstein e o nietzschiano Élie Faure tinham atribuído ao cinema. O que é, então, esse modo do mistério ou esse modo místico do sensível? É simplesmente o modo que abole a oposição entre um mundo interior e um mundo exterior, um mundo do espírito e um mundo dos corpos, que abole as oposições do sujeito e do objeto, da natureza cientificamente conhecida e do sentimento experimentado. O cinematógrafo, segundo essa lógica, é a arte "mística”, porque abole todas essas oposições. É a luz que escreve o movimento, a energia espiritual do sensível que revela a energia sensível do espírito.

Não se trata, evidentemente, de tomar essa "mística" do cinema como realidade empírica das formas existentes da indústria e das artes cinematográficas. $\mathrm{O}$ objetivo aqui é somente definir o tipo de historicidade em que se formula a natureza artística do cinema. O que é interessante, desse ponto de vista, é o seguinte: essa equivalência do interior e do exterior, do espiritual e do material, do científico e do sentimental tem um outro nome, um nome menos problemático que "mistério" ou "místico". Ela se chama simplesmente estética. É isso que significa a potência "estética" do cinema. As formas de escritura/luz do cinema são compreendidas dentro de uma estética geral, ou seja, de uma teoria geral da unidade do pensamento e do sensível, no pensamento de um mundo sensível idêntico ao mundo do pensamento,

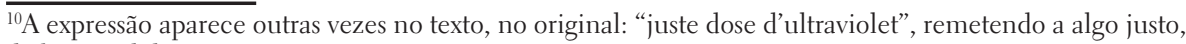
de boa medida. (N.T.) 
de um mundo de pensamento em si mesmo idêntico ao do não-pensamento. Esse é o modo estético da arte cinematográfica que se vincula ao advento de uma humanidade histórica nova, uma humanidade liberada das velhas falsidade e covardia do sujeito psicológico, uma humanidade também "honesta", que o artista vê, indo no mesmo ritmo que os movimentos verídicos da máquina. É esta humanidade do tempo do cinema, do tempo da estética, que clama o contemporâneo revolucionário dos jovens estetas franceses do cinema, Dziga Vertov: “A incapacidade dos homens em se darem por satisfeitos envergonha-nos diante das máquinas, mas o que vocês querem que se faça, se as maneiras infalíveis da eletricidade nos afetam ainda mais que a colisão desordenada dos homens ativos e a lassidão corruptível dos homens passivos?"11 (VERTOV, 1972). A complementaridade de uma humanidade atuando em desordem e de uma humanidade passiva e corruptível se alinhava à velha psicologia representativa da ordem da exploração econômica e da dominação política. O que lhe deve suceder é uma humanidade tendo superada esta dualidade psíquica e social, uma humanidade tendo a infalibilidade das maneiras de eletricidade porque ela possui a integridade do olho mecânico. E o cinema é a arte exatamente oferecida a esta humanidade.

É tudo isto que está implicado na natureza "estética" do cinema, que encerra a arte cinematográfica na historicidade de uma humanidade histórica nova. Certamente, pode-se considerar que esta configuração "histórica" do cinema pertenceria a uma ideologia bem datada: a dos anos 1920. Nesta época, em que quaisquer jovens estetas retiram o cinema de sua natureza de espetáculo popular e o elevam ao posto de um sacramento (a palavra é, ainda, de Jean Epstein), pertencente à nova aliança mística da arte e da ciência, do espírito e das massas, aquela à qual a Revolução Bolchevique dá a sua realidade concreta ${ }^{12}$. Ela não teria a ver com o "passado de uma ilusão"13, ruína entre ruínas empilhadas por dois séculos tomados pelo desatinado arbítrio de dar um sentido à história. O casamento místico entre arte e ciência, máquina e sensibilidade, poema e comunidade seria desembaraçar o intento comum destas utopias que nos fizeram tanto mal. E conviria separar a realidade do desenvolvimento de uma arte e de suas formas, assim como se precisa separar toda a utopia de um destino histórico e comunitário do real das forças e dos

\footnotetext{
${ }^{11} \mathrm{~A}$ edição mais recente é a feita por Annette Michelson. Kino-Eye: the writings of Dziga Vertov. Berkeley: University of California Press, 1984 (ver, em particular, p. 5-9, "We: variant of a manifesto"). (N.T.)

${ }^{12} \mathrm{O}$ período no idioma original (francês) está muito longo. No intuito de realizar uma tradução cuja leitura fique mais facilitada, o período foi separado em dois. (N.T.)

${ }^{13}$ A passagem refere-se a uma ideia marxista na qual as coisas hipoteticamente tomariam o seu curso prometido a partir de uma conscientização seguida da tomada de poder pelo proletariado, colocando, enfim, a história no que se imaginava como sua ordem natural, a inauguração de um mundo sem exploração de classes. (N.T.)
} 
interesses em jogo no concreto da política. Esta partilha razoável - e sempre retrospectiva - do real e da utopia me parece participar de uma sabedoria rasa e de curta visão. E em particular não acredito que a maneira como o cinema é "histórico" - que é historicizante e historicizável - possa ser separada deste núcleo utópico que se concentra em seu próprio nome, a escritura do movimento, e a escritura do movimento pela luz.

Podemos, certamente, relativizar as grandes utopias cinematográficas dos anos 1920, lembrar a maneira modesta como o cinema nasceu enquanto entretenimento popular, dizer que as teorias de Vertov e de Eisenstein, como as de Delluc ou de Epstein, são vinculadas a uma condição da técnica cinematográfica, e que o advento da fala e da indústria hollywoodiana trouxe de volta à sua medida exata a grande teoria da arte nova e da linguagem das imagens - tal como as realidades do comunismo soviético fizeram pelas grandes utopias simbólico-futuro-místico-revolucionárias ${ }^{14}$ do seu tempo. Todavia, me parece mais interessante demonstrar que ali existe mais que os modismos circunstanciais de uma época de confusão de ideias e áreas. Essas teorias poderiam servir de empréstimo aos temas e ao léxico de seu tempo. Mas a ideia de que a arte cinematográfica, como arte estética, é mais que a arte não é uma ideia circunstancial. Ela é inteiramente pré-formada na própria ideia da estética como regime histórico específico do pensamento das artes e ideia do pensamento concedido a este regime. A historicidade própria do cinema é de uma arte cujo conceito já existia previamente, um século antes da primeira grande sessão pública da Pathé.

Resumimos, assim, as quatro ideias que vimos definir a estética do cinema ao mesmo tempo que sua historicidade da arte. Primeiro, a ideia de arte antirrepresentativa, de arte que opõe o registro do pensamento "em toques de ampères", ou a radiografia do sentimento em ultravioleta, dos códigos expressivos da tradição representativa. Em seguida, ela é a ideia de arte como produto duplo, como unidade de um processo intencional e de um processo automático, sem consciência. É ainda a ideia de uma arte que manifesta um modo específico, um modo sobrenatural do sensível, abolindo as oposições tradicionais do sensível e da inteligibilidade, da ciência e da sensação ou do sentimento. É, enfim, a ideia de uma arte além da arte, uma arte que define um modo novo de ser em comum edificado das formas da vida comum. Ora, essas quatro ideias que definem a estética e historicidade do cinema foram todas previamente elaboradas e juntamente atadas um século antes - como podemos ver através dos grandes textos fundadores do romantismo, dos Fragmentos de Novalis ao Sistema do idealismo transcendental de Schelling e ao Mais antigo fragmento sistemático do idealismo alemão, que parece ter sido redigido em comum

${ }^{14}$ Original: symbolistico-futuro-mystico-révolutionnaires. (N.T.) 
por Hegel, Schelling e Hölderlin. Essas quatro teses fundamentais constituem a historicidade fundamental na qual o cinema está posto, a historicidade da estética.

Devemos apenas precisar o que é necessário entender pela noção de estética em sua generalidade de figura teórica e histórica da arte e do pensamento. A estética não é o nome neutro que designaria a ciência, ou a filosofia da arte, ou do belo em geral. Não é mais simplesmente o nome moderno dessa teoria que teria se imposto nos anos 1800. A estética é o conceito específico de um regime de pensamento das artes que é imposto em detrimento de um outro conceito, o de um outro regime poético das artes, a poética. Ela, de fato, não era a teoria da poesia. Era a teoria geral da arte, correspondente ao estatuto representativo da arte. Esse estatuto representativo não se esgota em si mesmo na ideia da natureza mimética das artes. A representação não é a única norma de semelhança de uma cópia em relação a um modelo, real ou ideal. Essa é a ideia de uma apropriação específica dos gêneros da representação e dos modos expressivos que elas ordenam aos sujeitos representados. É esse enquadramento das semelhanças e das conveniências pelo qual o gosto pode sentir e revelar a marca de natureza que dá sua validade à tekhné poiètikè ${ }^{15}$. Diante disso, a estética não é somente a "teoria", mas o regime de pensamento no qual as artes são desvinculadas das normas da representação, ou seja, deste sistema de equivalências, hierarquias e correspondências que distinguia os sujeitos nobres ou vulgares, as formas de sua correspondência e os tipos de situações e de expressões que eram apropriadas a ela. A estética é o regime de pensamento das artes em que "Yvetot vaut Constantinople", ${ }^{16}$ na qual nenhum sujeito nunca controla forma alguma nem estilo algum determinado, uma vez que todos os sujeitos são equivalentes em dignidade ou recebem bastante da sua dignidade da potência de arte de que se apoderam: o estilo como "maneira absoluta de ver as coisas". Tem-se frequentemente o juízo inconsequente de que esse estatuto absolutizado do "ponto de vista" e do ato artístico tenham sido subsumidos sob o termo estética, que nos reconduziria à passividade do sentimento ou da sensação. Mas não é nenhuma inconsequência.

\footnotetext{
${ }^{15}$ Tekhné poiètikè é a expressão em grego antigo utilizada desde Aristóteles para se referir às formas de fazer, de elaborar uma obra em forma de verso, com métrica (poíesis), derivada de um conjunto de elementos e habilidades necessários para sua confecção - em outras palavras, uma arte ou ofício (tekhné). A obra intitulada A Poética, de Aristóteles, trata justamente das formas, elementos e habilidades necessários para elaborar obras poéticas, derivadas do conceito central de mímesis, tradicionalmente traduzido como "imitação" ou mesmo "representação". Ver, para maiores informações: BAILLY, Anatole. Dictionnaire grec-français. Paris: Hachette, 1935. Disponível em: <https://archive.org/details/BaillyDictionnaireGrecFrancais $>$. Acesso em: 8 ago. 2017. (N.T.)

${ }^{16} \mathrm{~A}$ frase de Flaubert está contida em uma carta para Louise Colet de 1853, e diz: "Il n’y a pas en littérature de beaux sujets d'art et [...] Yvetot donc vaut Constantinople". Yvetot, uma pequena cidade francesa da região da Normandia, teria tanto valor - considerando sua lógica literária - quanto a capital do então Império Otomano, Constantinopla. (N.T.)
} 
O modo estético das artes dá a essa absolutização seu princípio teórico próprio. O fundamento teórico de absolutização do estilo é a ideia de um modo do sensível subtraído às conexões ordinárias da sensação assim como às lógicas psicológicas do sentimento, o modo de um sensível puro. E esse sensível puro é em si pensado como lugar de efetuação de um modo específico do pensamento, como unidade do pensamento e do não-pensamento, da consciência e da inconsciência. Assim nasce a estética, da conexão entre um regime de pensamento das artes e de uma ideia de pensamento. Ela nasce como o pensamento de um modo sensível, daquele que é ao mesmo tempo um modo espiritual do sensível. Essa ideia do pensamento está desde o início conectada a uma ideia de comunidade. A estética é o modo do pensamento da arte em que a arte é sempre mais que arte, pela qual é um modo de efetivação próprio do pensamento que produziu formas de vida, formas de realidade concreta e sentido das ideias. Ela é o pensamento do devir sensível que torna as ideias comuns, que dá a uma comunidade a posse das formas sensíveis de sua ideia. Produzir as ideias sensíveis para torná-las "populares", para abolir a separação entre os que pensam sem sentir e os que sentem sem pensar, é o mais antigo programa da estética. O programa na qual ela se afirma, ao tempo em que Schiller produziu o estado estético e de educação estética, a mediação entre o mundo da necessidade e o mundo da liberdade, ao tempo em que Hölderlin sonhou a igreja estética e escreveu com Hegel e Schelling este rascunho que projeta uma "estetização" das ideias da razão, assimilada a uma "mitologia racional". Sem dúvidas esse programa pode conhecer as formas mais diversas, da educação estética de Schiller ao mito wagneriano, ou os "ofícios" ${ }^{17}$ mallarmeanos. No entanto, ele é dominado por uma ideia fundamental comum: a arte é quem dá à comunidade política suas formas de comunidade sensível que unem seus homens em seus vínculos vivos, opostos à abstração da lei. Tece esse tecido sensível notável do mundo comum, essa "magnificência qualquer" que Mallarmé vê ao substituir "o homem de outrora”, ou seja, a transcendência religiosa e a comunidade da fé. A arte é também tendenciosamente a vida, é o pensamento que se tornou tecido sensível da vida, ritmo da comunidade, por isso mesmo, mito comunitário. O modo estético da comunidade é o modo de uma comunidade pensando o que ela sente e sentindo o que ela pensa.

Este é o programa estético do pensamento, da arte e da comunidade que guarda um destino para o cinema, que elabora o conceito de uma arte propriamente estética: uma arte desvinculada do sistema representativo e vinculada a uma

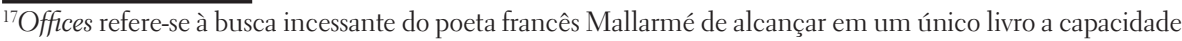
de transcender todo o ecletismo das artes, atingindo o potencial de um fenômeno em sua totalidade. De certa maneira, o cinema traria de volta esse programa estético lançado pelos idealistas alemães citados no parágrafo: Friedrich Schiller, Friedrich Hölderlin, Georg W. F. Hegel e Friedrich W. J. von Schelling. (N.T.)
} 
ordem social hierárquica. Uma arte idêntica a uma sensibilidade pura, igualando a intencionalidade consciente de toda tekhné à realização não-intencional de um pensamento inconsciente. Essa união do pensamento e do sensível, do consciente e do inconsciente, que é posta em 1801 como o "próprio da arte", no Sistema do idealismo transcendental de Schelling, aparece como exatamente realizado por essa "raiz quadrada da imagem" que resulta, segundo Epstein, da união entre o olho consciente do cinegrafista e o olho inconsciente do cinematógrafo. O cinema é a arte que realiza a identidade de um modo sensível de pensamento e de um modo pensante da matéria sensível. Subitamente ele aparece como a arte própria à comunidade estética. Nos anos 1800, os românticos alemães haviam oposto o Estado livre das ideias estetizadas ao Estado mecânico da lei. Nos anos 1830, os saint-simonianos haviam deslocado a oposição da máquina e do ser vivente. À "mecânica" do Estado e da lei, haviam oposto o casamento da palavra e da comunicação viva que constituiu a ferrovia, a máquina que colocou os homens verdadeiramente, materialmente, em ligação uns com os outros, e o coro $^{18}$ dos construtores operários animados por um pensamento estetizado, que se tornou hino comunitário. E todo o século XIX havia sonhado sob a liberdade nova que simbolizou a energia elétrica, a energia de uma matéria imaterializada, transformada em espírito e ligação espiritual. A invenção cinematográfica se inscreve nessa filiação. A máquina cinematográfica herda a dupla vocação da máquina exata e do hino comunitário novo, a grande sinfonia das imagens que uns remetem à sinfonia beethoveniana e wagneriana, e outros aos afrescos, ou aos grandes poemas em pedra dos povos de outrora. Pelo cinema, Élie Faure vê a roda do espírito das formas recomeçar seu ciclo, passar da dissolução espiritual da música à nova sinfonia dos construtores (FAURE, 1953). A historicidade-cinema, propriamente, é o ser efetivo de uma ideia de século. O cinema é a ideia de arte que carregou por um século inteiro, sendo a arte do século XX pensada pelo século XIX: predeterminado pelas categorias do pensamento estético, mas também pela ideia do "século", pela ideia da religião secularizada que essas categorias têm elaborado como ideia de aliança comunitária.

O "documentário histórico" de Jennings nos revelava assim, passo a passo, como a capacidade de "mostrar" a história remonta a uma historicidade

\footnotetext{
${ }^{18}$ Esta referência está relacionada à pesquisa feita por Jacques Rancière, publicada em seu livro La nuit des prolétaires, em que trata, entre outros assuntos, dos movimentos operários e da imprensa operária na década de 1830. Em vez de notar uma identificação com uma ideia pressuposta de "classe", o autor percebeu nas fontes da imprensa operária uma forma de pensar a liberdade de um modo muito semelhante à ideia de um "estado estético do homem" - inspirado nas ideias de Schiller - em que o trabalho seria superado pela arte e pela beleza como fator de união comunitária. RANCIÈRE, Jacques. La nuit des prolétaires. Paris: Fayard, 1981. (N.T.)
} 
mais fundamental do cinema. E, sem dúvida, o filme documentário é um suporte privilegiado dessa demonstração. Se o cinema é a arte romântica por excelência, a arte da combinação dos sinais da natureza, de intensidade e de significância variáveis, o filme documentário é o cinema por excelência. Sua vocação o leva a exceder duplamente as normas da representação ficcional, do lado da fidelidade maquínica ao real da visão e, ao inverso, do lado do livre agenciamento dos signos por dentro do cérebro do artista. Desobrigado, por sua própria vocação ao "real", das conveniências e das verossimilhanças da representação, ele pode unir o poder de impressão, o poder da palavra que nasce do encontro do mutismo da máquina e do silêncio das coisas, com o poder da montagem que constrói uma história e um sentido, pelo direito que se arroga a combinar livremente as significações e limitar ou ampliar sua potência de sentido e de expressão. Ainda hoje, ele é o mais confortável diante das transformações da máquina de visão em máquina de escrita. As sobrecargas das palavras e das imagens sobre a tela/quadro das Histoire(s) du cinéma de Godard ou as decomposições e recomposições virtuais da batalha de Okinawa no Level five de Chris Marker (Nível cinco, 1997) opõem sua potência estética e intelectual da história a essa "perda do visível" que tanto significam, para muitos dos comentadores, o vídeo e a imagem numérica. É que o "documentário”, por seus atributos, realiza em sua radicalidade essa identidade do pensamento, da escrita e do visível, que é o mesmo nó do pensamento estético e de sua capacidade "histórica".

Em contrapartida, está claro que a ficção cinematográfica pouco se conforma à vocação estética que tinham atribuído a ela, como vocação histórica, os teóricos dos anos 1920. Mas não é suficiente para dizer, minimamente, que o advento da fala e da indústria hollywoodiana da ficção arruinaram o grande sonho histórico do cinema, ou o teriam reenviado ao seu estado de utopia inconsistente. A tradição hollywoodiana não somente restituiu o privilégio "poético" da palavra que construiu um visível “à sua imagem”. Ela também reintroduziu todo o sistema de gêneros: a aliança de um gênero a um tipo de sujeito, os códigos das verossimilhanças e das conveniências, os personagens e as situações-tipos, as formas e modos de expressão vinculados aos gêneros. E, de encontro ao grande sonho de seus profetas, o cinema tornou-se, em nosso século, o porta-bandeira ${ }^{19}$ do sistema representativo, deposto alhures ou invalidado. Mas a relação não é apenas entre arte e indústria, não mais que entre utopia e realidade. Em primeiro lugar, a relação é entre lógica poética

\footnotetext{
${ }^{19}$ No original: porte-flambeau, expressão literalmente traduzida como "portador da tocha", é utilizada com significado de condução, algo que representa e fala em lugar de alguém, uma classe, ou teoria. Preferiu-se traduzir, neste caso, pela expressão "porta-bandeira", por ser mais comum no idioma português do que a tradução literal em francês. (N.T.)
} 
e lógica estética. Essa não é uma relação de exclusão, mas de entrelaçamento. A lógica estética pretende transformar em pura linguagem das sensações o jogo das equivalências representativas entre a linguagem e as formas do visível. Mas nenhuma arte da ficção jamais conduziu essa transformação a seu termo. O cinema mudo, como se fez frequentemente observar, jamais teria sido uma pura língua das imagens. Delluc já denunciou a inconsequência dos intertítulos ${ }^{20}$ de La roue (A roda, 19211923), de Abel Gance, que retraduziam na linguagem da velha psicologia romanesca a grande sinfonia do homem e da máquina. Mas, sem mesmo falar do papel da palavra, as expressões da fisionomia dos heróis de Coeur fidèle (Coração fiel, 1923), de Jean Epstein, são seguramente mais próximas da psicologia dos folhetins que da "justa dose de ultravioleta" registrada pelo arco elétrico. Para os pioneiros mais intransigentes, a arte cinematográfica nunca foi admitida como pura linguagem das imagens. Mas, inversamente, não mais a negou, mesmo em suas formas representativas mais banalizadas. E seria interessante fazer a "história do cinema" como história das relações de conflito e entrelaçamento entre essas duas lógicas. Poderíamos, deste ponto de vista, retomar a história da "mise en scène" cinematográfica. Esse termo aparece naturalmente, mas também paradoxalmente. Não remete ele apenas ao dispositivo do teatro, e então a tudo aquilo de que a vontade estética do cinema quis se desvencilhar? Mas, para o termo de mise en scène, assim como para o de estética, a objeção é superficial. Por que a mise en scène não é nenhuma arte auxiliar do teatro, dependente da tradição representativa. Ela é uma arte completa, uma arte apropriada à era estética, que está justamente comprometida em substituir a antiga assistência visual da gesticulação e do cenário por uma encenação da potência sensível do pensamento do poema dramático: não uma figuração do que dizem suas palavras, mas uma música visível da potência da palavra que se manifesta sem dizer. Também a "cinegrafia” teorizada por Delluc, Epstein ou Élie Faure e realizada por Chaplin ou Vertov pertence à mesma tradição estética que a "cenografia" de Craig, de Appia ou de Mayerhold. Sobre a tela cinematográfica se disputa uma mesma batalha, a da lógica estética e da lógica representativa na cena dos novatos da mise en scène. E, sem dúvida, poderíamos comparar o destino das duas artes e dizer que, tendencialmente ${ }^{21}$, a cinegrafia perdeu ao longo do século essa autonomia estética que parecia privilegiar seu próprio dispositivo técnico, enquanto a cenografia tem

\footnotetext{
${ }^{20}$ Durante a exibição de um filme mudo, os intertítulos (cartelas com escritos) apareciam entre as imagens-movimento explicando a cena, ou no lugar de um diálogo importante na resolução da trama entre as personagens. Com o advento do cinema sonoro, os intertítulos permaneceram, indicando localização no espaço e no tempo. (N.T.)

${ }^{21}$ “Tendencialmente" (tendanciellement) parece uma tradução mais adequada, por não ter a carga de "tendenciosamente" (tendancieusement). (N.T.)
} 
ganhado sua disputa contra o velho teatro. Mas essas avaliações de tendências "históricas" são pouco interessantes. Vale mais a pena analisar a mise en scène do cinema como o conflito interminável das poéticas, e de que maneira pôr em questão, através deste conflito, as formas próprias do visível.

A partida se joga, então, não mais a dois, mas a três. Existe a lógica estética da cinegrafia, com sua exigência dos gestos exatos do pensamento "imprimindo toques de ampères na tela”. Há a lógica representativa, com suas codificações dos sujeitos e dos gêneros, das situações e dos personagens, dos afetos e das expressões. E há as lógicas artísticas singulares, que se instalam na relação das duas e no conflito das visibilidades que esta relação institui. Mas também o "representativo" e o "estético" não são apenas categorias da arte. São categorias que conectam um regime de objetos e de procedimentos artísticos com as formas de partilha do sensível que especificam uma comunidade. O "representativo" remete a uma distribuição de papéis, de situações e de comportamentos sociais. A "estética" remete aos modos da percepção do sensível comum. E o procedimento artístico que entrelaça os dois regimes coloca também em ficção as próprias formas do visível e do sensível que definem a partilha de um mundo. Podemos tomar como exemplo as ficções langianas do visível e do oculto que jogam entre três coisas: o topos representativo do declínio do lado oculto das coisas; o poder da decupagem do visível próprio à câmera; e as transformações das formas do visível e do dizível, do público e do privado que regem o modo de vida de uma sociedade. Exemplar, deste ponto de vista, é a ficção cinematográfica de While the City Sleeps (No silêncio de uma cidade, 1956), de Fritz Lang. O cenário põe a câmera em um ambiente específico: a face obscura da grande máquina de escrita e de visibilidade que se chama jornalismo ${ }^{22}$. Nesse cenário, a trama do filme se constrói pela relação de dois regimes do visível. Há, de um lado, a velha caricatura representativa em que se comprazem os projetistas que acreditam dirigir com sua palavra astuciosa a aparência das coisas e cuja exibição virtuosa de Ida Lupino ${ }^{23}$ exalta a potência. Há, de outro lado, a figura nova, a figura surpreendente e inquietante que tomou a grande utopia da linguagem universal das imagens. O "artista honesto" de Epstein, as "maneiras infalíveis da eletricidade" de Vertov são tornadas máquina televisiva. Esta instala o honesto jornalista Mobley no domicílio do criminoso/vítima, o mestre que comanda a operação policial, fingindo saber o que ele ignora e ver o que ele não vê: e sua vítima se toma, de fato, neste cara a cara imaginário. Pode-

\footnotetext{
${ }^{22}$ No filme de Lang, há um jogo de câmera que põe, ainda que indiretamente, de um lado o jornalista Mobley afirmando que sabe quem é o criminoso referente à sua notícia e que vai encontrá-lo; de outro, o criminoso que acompanha o noticiário pela televisão e assiste à acusação do jornalista, como se estivessem face a face. (N.T.)
}

${ }^{23}$ Ida Lupino (1918-1995), britânica radicada nos EUA, foi atriz, roteirista e produtora de cinema. (N.T.) 
se dizer, parafraseando uma célebre frase de Canguilhem, que a invenção estética das imagens falantes fez por sua conta o caminho, como quem da Sorbonne desce à sede da polícia ${ }^{24}$. Exceto, claro, que se Mobley fez descer a câmera da televisão Kyne para a sede da polícia, Lang toma, com a dele, a direção inversa do Panthéon, que o cinema, em seu filme, se olha e se põe em cena em seus futuros possíveis: seu devir-teatro como seu devir-televisão. A história da mise en scène cinematográfica não é, assim, a história do sombrio destino que transformaria a cinegrafia no velho teatro ou a levaria a se perder na imagem televisiva, consagrando também a vingança do "combate desorganizado dos homens ativos" e a "lassidão corruptível dos homens passivos" sobre o artista "incorruptível sem complacência, inteiramente honesto", da visão maquínica. O modo estético da arte e do pensamento nunca tem precisamente, em seus trabalhos, a pureza de seus manifestos. Não se trata da diferença do real e da utopia. O modo estético da arte é constitutivamente condenado a pôr em cena a sua contradição. E o cinema, arte estética por excelência, mantém daí sua potência de historialidade e de historicização.

\section{Referências}

BAILLY, A. Dictionnaire grec-français. Paris: Hachette, 1935. Disponível em: <https:// goo.gl/B3dKKw>. Acesso em: 17 out. 2017.

EPSTEIN, J. Écrits sur le cinéma:. 1920-1953. Paris: Seghers, 1975. 2 v.

FAURE, É. Fonction du cinema: de la cineplastique a son destin social. Paris: Gonthier, 1953.

MICHELSON, A. Kino-Eye: the writings of Dziga Vertov. Berkeley: University of California Press, 1984.

RANCIÈRE, J. La nuit des prolétaires: archives du rêve ouvrier. Paris: Fayard, 1981.

Os nomes da história: um ensaio poético do saber. Tradução Eduardo Guimarães e Eni Orlandi. São Paulo: EDUC; Pontes, 1994.

SCHNAPPER, L. "Histoire de la musique: chanter la romance". Napoleonica: La Revue, Paris, v. 7, n. 1, p. 3-20, 2010. Disponível em: <https:/goo.gl/6ZrgcA $>$. Acesso em: 17 out. 2017 .

VERTOV, D. Articles, journaux, projets. Tradução Sylviane Mossé e Andrée Robel. Paris: Union Générale d'Editions, 1972.

\footnotetext{
${ }^{24}$ Georges Canguilhem (1904-1995) encerrou uma conferência sobre a história das ciências constatando que, ao sair da Sorbonne, se sobe a rua Saint-Jacques, em Paris. Percorrendo a direção acima, se faz o caminho que leva ao Panthéon, lugar dos grandes homens, heróis da pátria etc., mas, ao descer a rua, certamente se chegará à Sede da Polícia e, de fato, o autor concluiu que as ciências humanas fariam mais por si mesmas descendo a rua do que subindo. (N.T.)
} 


\section{Referências audiovisuais}

COEUR Fidèle. Jean Epstein, França, 1923.

HISTOIRE(S) du Cinéma. Jean-Luc Godard, França, 1998.

LA Roue. Abel Gance, França, 1923.

LEVEL Five. Chris Marker, França, 1997.

LISTEN to Britain. Humphrey Jennings, Reino Unido, 1941.

LONDON Can Take It. Humphrey Jennings, Reino Unido, 1940.

WHILE the City Sleeps (No silêncio de uma cidade). Fritz Lang, Estados Unidos, 1956.

submetido em: 3 jun. 2017 | aprovado em: 6 out. 2017 